GEOPHYSICAL RESEARCH LETTERS, VOL. 12, NO. 7, PAGES 461-464, JULY 1985

\title{
EFFECT OF THE INTERPLANETARY MAGNETIC FIELD Y COMPONENT ON THE HIGH-LATITUDE NIGHTSIDE CONVECTION
}

\author{
O. de la Beaujardière, V. B. Wickwar, J. D. Kelly
}

SRI International, Radio Physics Laboratory, Menlo Park, California

J. H. King

National Space Science Data Center, NASA Goddard Space Flight Center, Greenbelt, Maryland

\begin{abstract}
Sondrestrom radar observations reveal that the dawn-dusk $\left(B_{y}\right)$ component of the interplanetary magnetic field (IMF) strongly influences the nightside polar convection. This effect is quite complex. The convection for one orientation of $B_{y}$ is not the mirror image of the other orientation. A positive $B_{y}$ (i.e., pointing toward dusk) seems to organize the velocities such that, at all local times, they are predominantly westward within the radar field-of-view ( $\simeq 68^{\circ}$-to- $82^{\circ}$ invariant latitude). Between dusk and midnight, on one such occasion, sunward flow is observed within the polar cap. In the midnight and dawn sectors, when $B_{y}$ is negative, the plasma velocities often appear random. For large negative $B_{y}$, the afternoon cell appears shifted toward early hours such that large southward velocities are observed about 3 hours before midnight. These are the only times when the predominant velocity component is southward.
\end{abstract}

\section{Introduction}

The effect that the dawn-dusk (y) component of the IMF has on the polar ionospheric convection is still poorly known in spite of the fact that it has been the object of several recent investigations [see for example, FriisChristensen et al., 1985, and references therein]. As an example, the last three publications on the subject each propose a different convection pattern for a given IMF orientation [Zanetti et al., 1984; Reiff and Burch, 1985; Friis-Christensen et al., 1985]. The focus of most studies of the $B_{y}$ effect has been on the noon local time sector. In this paper, we concentrate on the nightside of the auroral zone and polar cap, using Sondrestrom radar measurements of convection.

The electric field and electron density measurements were obtained during $24-\mathrm{hr}$ experiments. The latitude coverage was $68^{\circ}$ to $82^{\circ}$ invariant latitude $(\Lambda)$. [The radar and operating mode are described in Wickwar et al. (1984) and references therein.] The IMF was measured from the IMP 8 spacecraft. We examined the fourteen such 24-hr runs for which IMF measurements were available. (Note, however, that the IMF data are not continuous; at times, large gaps are present in the data.) Particle data from the Defense Meteorological Satellite Program (DMSP) [Gussenhoven et al., 1983] were used to indicate the position of the auroral oval.

Copyright 1985 by the American Geophysical Union.

Paper number 5L6543.

0094-8276/85/005L-6543\$03.00

\section{The Observations}

Figure 1 shows plots of convection velocities for four experiments. These examples were selected because they illustrate the main features observed. The figure shows, for each experiment, the IMF orientation and the plasma convection. The velocity vectors are plotted in a clock-dial format, color-coded such that blue and red are for velocities with east and west components, respectively. The $B_{Z}$ (northsouth) and By vectors in the Geocentric Solar Magnetospheric System (GSM) are represented in the inside circle using a similar color convention. As shown in figure 1d, positive $B_{Z}$ points toward the center of the circle, and positive $B_{y}$ towards the west direction. The vectors are red and blue for positive and negative $B_{y}$, respectively. The two sketches of convection patterns, reproduced in Figure 2 from Reiff and Burch [1985] and Potemra et al. [1979] are both for $B_{Z}>0$. The one on the left (right) is for $B_{y}$ positive (negative). As will be shown below, in the dawn and dusk sectors the observations match fairly well these sketches, but not in the midnight sector.

\section{IMF By Positive}

We first turn our attention to observations when $B_{y}$ was positive. The first example is the April 23-24, 1983 experiment (Figure 1a). At 2100 UT the IMF By component changed from negative to positive. The convection responded almost instantly to this change (i.e., within the temporal resolution of the radar mode), becoming sunward (westward) within the entire field-of-view $\left(\Lambda=68^{\circ}\right.$ to $\left.82^{\circ}\right)$. Excluding a brief moment of plasma flow in the southward direction (2345 UT), the flow remained sunward over the radar field-of-view for as long as $B_{y}$ remained positive (6 hours). Even as $B_{Z}$ became southward, the velocities remained westward.

To see if this wide region of sunward flow was associated with auroral oval precipitation, we examined data from the DMSP satellite. A satellite overpass occurred at 2200 UT, $15^{\circ}$ east of Sondrestrom. Following the procedure outlined by Gussenhoven et al. [1983] the location of the auroral oval boundaries can be determined. The oval is defined as the region where the integral number flux and the energy flux rise noticeably above background. The poleward limit of the oval was at $\Lambda=69.6^{\circ}$ as shown in Figure la. Therefore, the auroral precipitation was near the southern limit of the radar field-of-view, and the sunward flow observed around 2200 UT was within the polar cap. This conclusion is supported by the radar electron-density measurements, which showed no auroral precipitation. Except for a brief period at 


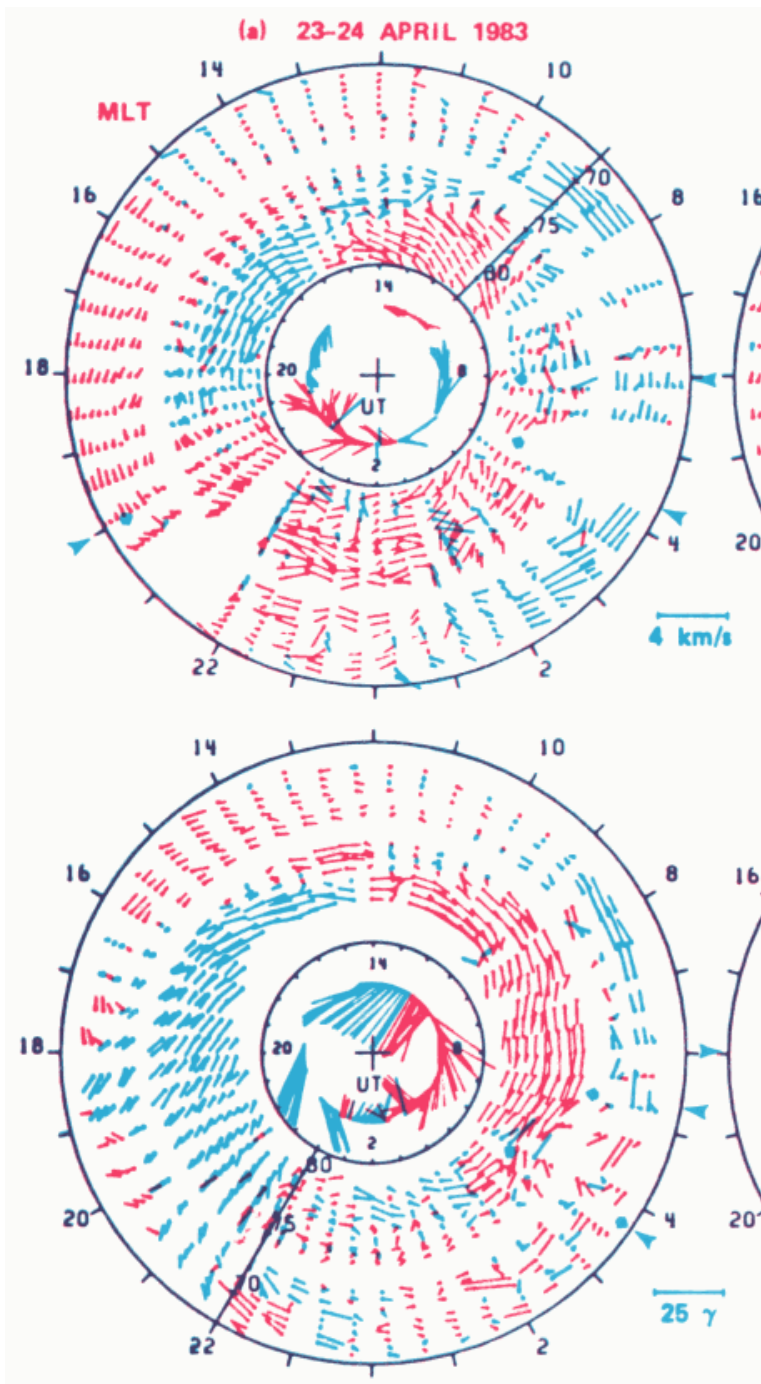

(c) 23 JULY 1983 (b) 13-14 JULY 1983
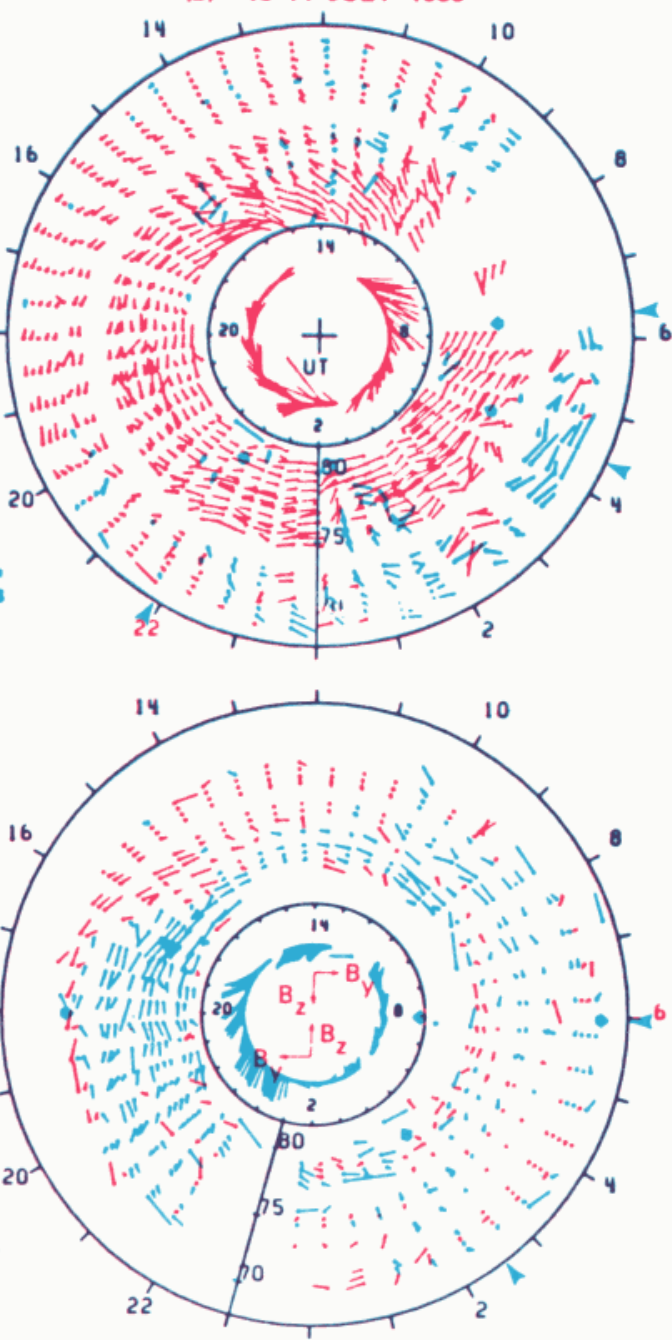

(d) 18 JANUARY 1984

Fig 1. Plasma drift and IMF vectors for four typical examples. The thick blue arrows indicate the poleward or equatorward boundaries of the auroral oval, as determined from coincident DMSP passes. The times at which the satellite passes occurred are marked by a thinner arrow on the periphery.

$2400 \mathrm{UT}$, the E region density remained small ( $\mathrm{Ne}<3 \times 10^{4}$ at $150-\mathrm{km}$ altitude) until $0300 \mathrm{UT}$, when the IMF changed orientation. Consequently, the west ward velocities observed between 0010 and 0310 UT were also within the polar cap, at least between $\Lambda=72.5^{\circ}$ and $76^{\circ}$, the radar field-of-view at $150 \mathrm{~km}$ altitude.

We should point out however that soft-particle precipitation was observed poleward of the auroral oval. Bursts of electron precipitation are seen in the DMSP data, between the two auroral oval crossings. In addition, analysis of the radar $F$-region temperatures and density suggests that soft electrons were precipitated. In this paper, polar cap and auroral oval are defined in terms of their signature in the electron and proton detectors on board DMSP, and in the radar-measured $\mathrm{E}$ region density.

Another example of IMF By $>0$ is the July 13-14, 1983 experiment (Figure 1b). The IMF By was large and positive (between 5 and $10 \gamma$ ) during virtually the whole observation period. Most or all the latitudes probed by the radar were within regions of westward velocity. It appears that the radar remained under a large westward vortex for 24 hours. The pattern is not a snapshot. In fact, the pattern probably 

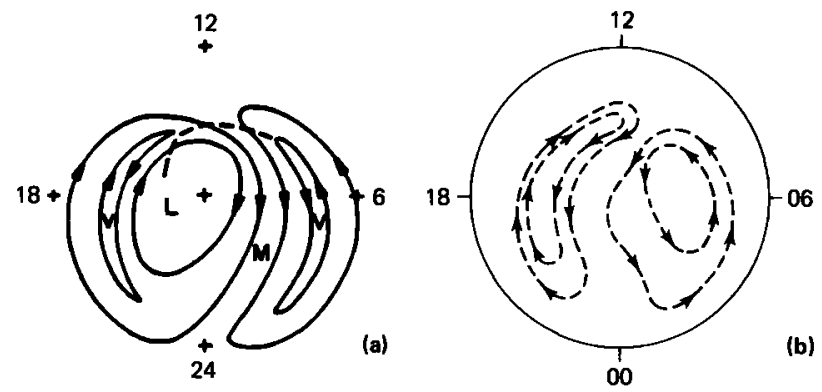

Fig. 2. Convection patterns from (a) Reiff and Burch [1985], and (b) Potemra et al. [1979] for By positive and negative, respectively.

changed substantially around $1300 \mathrm{UT}$. At this time the geomagnetic activity abruptly decreased. [The AE index, which had averaged $\simeq 500 \gamma$ during the previous 24 hours, decreased to $\simeq 100 \gamma$ at this time and remained low until the end of the experiment (H. Kroehl, private communication, 1984).] Nevertheless, this example is typical of other observations in the sense that, when $B y>0$, the convection remains westward within the poleward part of the field-ofview at all local times, and it is often westward within the whole field-of-view in the premidnight sector.

Premidnight on July 13-14, the velocities were westward within almost the entire field-of-view, as was the case on April 24 (Figures 1a and b). However, contrary to April 24, most of the radar field-of-view was within the auroral oval, as indicated by particle data from a coincident DMSP overpass and by radar data that show energetic particle precipitation (the oval poleward boundaries determined from DMSP are shown in Figure 1b).

Gaps in the data occurred on July 13 while the radar was in the dawn sector. The July 23, 1983 data (Figure 1c) offer a better example in this time sector. An examination of these two July dawn sector observations reveals that when $B_{y}$ is positive and $B_{z}$ negative, a strong antisunward flow is observed north of $\Lambda \simeq 76$, and a sunward flow is observed south of this latitude. The velocities often exceed $2000 \mathrm{~m} / \mathrm{s}$ and their north-south (N-S) components are small compared to the east-west (E-W) components. In fact, the E-W component is dominant at all local times in virtually all observations when $\mathbf{B}_{\mathbf{y}}>0$.

\section{IMF By Negative}

Cases of observations while $\mathbf{B}_{\mathbf{y}}$ was negative are found on April 24, July 23, 1983 and January 18, 1984 (Figure 1). (The July 23 experiment is unusual because it corresponds to the largest $\mathbf{B}_{\mathbf{y}}, 25 \gamma$, seen so far during Sondrestrom operations.) The January 18 conditions are of interest because they are symmetric to those of July 13 in the sense that IMF By was strong on both days but of opposite polarity.

The dusk sector in these examples is characterized by antisunward velocities within most or all of the field-of-view and by sharp reversals (for example January 18 1700 UT). A coincident DMSP overpass indicated that around 2000 UT on January 18, the convection reversal was collocated with the poleward oval boundary (Figure 1d).
As the local time approaches magnetic midnight, the relative importance of the N-S component increases such that around 1900 to $2000 \mathrm{MLT}$, the E-W component is very small, and the flow is nearly equatorward.

The midnight and dawn sectors are characterized by fairly small and irregular velocities. At times, several reversals occur within the field-of-view (see for example, January 18 after 0200 UT and April 230600 to 0900 UT).

\section{Observation Summary and Discussion}

In spite of the limited number of observations when IMF data are available, a few salient features have emerged so far from the data, which can be summarized as follows:

Conclusions for $B_{y}$ positive: (1) The velocities are predominantly westward at all local times at the latitudes covered by the radar. This remains true even when $\mathbf{B}_{\mathbf{y}}$ is small. In the afternoon convection cell, the sunward (westward) flow spans most latitudes; in the morning convection cell antisunward (westward) velocities are seen poleward of a sharp convection reversal. (2) On April 23-24, sunward flow was observed in the polar cap in the premidnight sector, between 2100 and 0300 LT (2200 and 0400 MLT).

Conclusions for $B_{y}$ negative: (1) A sharp reversal is observed in the dusk cell. It is only in this dusk sector that velocities are predominantly eastward within the field-ofview. (2) A feature only observed when $B_{y}<0$ is that, before midnight, the dominant flow component is southward. (3) The midnight and dawn sectors are characterized by smaller, fairly irregular velocities.

Observations of sunward flow within the polar cap have been reported previously [e.g., Heppner, 1972; Burke et al., 1979; Burch et al., 1985]. What is new here is that, even close to midnight, and as far as $\sim 15^{\circ}$ from magnetic pole, sunward (westward) drift is observed in the polar cap. A difficulty, however, in drawing a parallel between different sets of observations is that, to each set of instruments, there corresponds a different definition of polar cap. The issue of defining exactly the polar cap is very complex, still unresolved [Torbert et al., 1981], and not within the scope of this paper.

Our observation of disorganized velocity vectors when $\mathrm{B}_{\mathbf{y}}$ is negative, is reminiscent of Birkeland-current observations from MAGSAT [Iijima et al., 1984]. At local times between dusk and dawn, the MAGSAT satellite observations reveal that field-aligned currents are highly structured, and form a pattern that is not persistent from one pass to the next. However, these observations were only for $\mathbf{B}_{\mathbf{Z}}>0$. The radar data seem to indicate that disorganized velocities are also observed when $\mathrm{B}_{\mathrm{Z}}<0$; additionally, they seem to be a characteristic of a negative $B_{y}$ orientation.

\section{Conclusion}

In conclusion, the observations described in this paper indicate that the effect of the By component is not limited to the noon hours, but is felt at all local times. It is clear that the convection pattern is not symmetric for opposite $B_{y}$ directions. That is, the convection pattern for $B_{y}>0$ is not the mirror image of that for $\mathrm{B}_{\mathbf{y}}<0$. This finding is contrary to the models proposed by Burch et al. [1985] and Reiff and 
Burch [1985], Potemra et al. [1984], or by Zanetti et al. [1984]. However, these models were based on observations close to magnetic noon. On the other hand, empirical models proposed by Heppner [1977], or Friis-Christensen et al. [1985], based on observations at later local times, are not symmetric for opposite $B_{y}$ directions.

This asymmetry in the nightside of the convection may be attributed to the role of the IMF $B_{X}$ component, as was proposed by Heelis [1984] to explain noontime observations. Reiff and Burch [1985] have suggested that in the polar cap the plasma flows within a distinct and separate "lobe cell," marked L on Figure $2 a$. The flow within it is clockwise when $B_{X}$ is negative and $B_{y}$ positive, which was the IMF configuration during the radar observations on April 23-24 when sunward flow was recorded poleward of the auroral oval. Consequently, the region of westward flow observed with the radar when $B_{y}>0$ may, at times, be part of the "lobe cell." However, the reversal due to the viscous cell ("V" in Figure 2a) is not apparent in these data, nor in the other 24-hr periods of observations. Thus, the radar observations are more consistent with a single cell in the dusk sector as proposed by Potemra et al. [1979]. More observations are required, with all possible orientations of $B_{X}$ and $B_{Y}$ to determine if the observations are consistent with the existence of a "lobe cell," and to fully assess the influence of $\mathrm{B}_{\mathrm{X}}$.

In this paper, we have tried to isolate the effects of IMF $B_{y}$, but the convection also depends on other factors such as season, $B_{Z}$, magnetic activity, or the presence of substorms. It is not easy to assess the relative importance of all of these factors. Work has started on a statistical study of the relationship between the IMF orientation and the convection pattern. As more observations become available, our confidence in this statistical study will increase. The coincident data from Millstone Hill and EISCAT will also be incorporated to extend the coverage of the observations.

Acknowledgments. This work was supported by NSF coop agreement ATM8121671 and AFOSR contract F49620-83-K-0005. Our thanks go to S. Gussenhoven, D. Hardy, and N. Heinnemann who provided the DMSP data.

\section{References}

Burch, J. L., P. H. Reiff, J. D. Menietti, R. A. Heelis, W. B. Hanson, S. D. Shawhan, E. G. Shelley, M. Sugiura, D. R. Weimer, and J. D. Winningham, IMF $B_{y}$-dependent plasma flow and Birkeland currents in the dayside magnetosphere. 1. Dynamics Explorer observations, J. Geophys. Res., 90, 1577, 1985.

Burke, W. J., M. C. Kelley, R. C. Sagalyn, M. Smiddy, and S. T. Lai, Polar cap electric field structures with a northward interplanetary magnetic field, Geophys. Res. Letts., $6,21,1979$.
Friis-Christensen, E., Y. Kamide, A. D. Richmond, and S. Matsushita, Interplanetary magnetic field control of high-latitude electric fields and currents determined from Greenland magnetometer data, J. Geophys. Res., 90, 1325, 1985.

Gussenhoven, M. S., D. A. Hardy, and N. Heinemann, Systematics of the equatorward diffuse auroral boundary, $J$. Geophys. Res., 88, 5692, 1983.

Heelis, R. A., The effects of interplanetary magnetic field orientation on dayside high latitude ionospheric convection, J. Geophys. Res., 89, 2873, 1984.

Heppner, J. P., Polar-cap electric field distributions related to the interplanetary magnetic field direction, J. Geophys. Res., 77, 4877, 1972.

Heppner, J. P., Empirical models of high-latitude electric fields, J. Geophys. Res., 82, 1115, 1977.

Iijima, T., T. A. Potemra, L. J. Zanetti, and P. F. Bythrow, Large-scale Birkeland currents in the dayside polar region during strongly northward IMF: A new Birkeland current system, J. Geophys. Res., 89, 7441, 1984.

Potemra, T. A., T. Iijima, and N. A. Saflekos, Large-scale characteristics of Birkeland currents, in Dynamics of the Magnetosphere, p. 165, D. Reidel, Hingham, Mass., 1979.

Potemra, T. A., L. J. Zanetti, P. F. Bythrow, and A.T.Y. Lui, $\mathrm{B}_{\mathrm{y}}$-dependent convection patterns during northward interplanetary magnetic field, J. Geophys. Res., 89, 9753, 1984.

Reiff, P. H. and J. L. Burch, IMF By-dependent plasma flow and Birkeland currents in the dayside magnetosphere. 2. A global model for northward and southward IMF, $J$. Geophys. Res., 90, 1595, 1985.

Torbert, R. B., C. A. Cattell, F. S. Mozer, and C.-I. Meng, The boundary of the polar cap and its relalion to electric fields, field-aligned currents, and auroral partici' preeipitation, Physics of Auroral Arc Formation, Anserican Geophysical Union, 1981.

Wickwar, V. B., J. D. Kelly, O. de la Beaujardière, C. A. Leger, F. Steenstrup, and C. H. Dawson, Sondrestrom overview, Geophys. Res. Letts., 11, 883, 1984.

Zanetti, L. J., T. A. Potemra, T. Iijima. W. Baumjohann, and P. F. Bythrow, Ionospheric and Birkeland current distributions for northward interplanetary magnetic field: Inferred polar convection, J. Geophys. Res., 89, 7453, 1984.

O. de la Beaujardière, V. B. Wickwar, and J. D. Kelly, SRI International, Menlo Park, CA 94025.

J. H. King, National Space Science Data Center, NASA Goddard Space Flight Center, Greenbelt, MD 20771.

(Received April 15, 1985; accepted May 7, 1985) 